\title{
COMBATING LAND DEGRADATION AND PROMOTING SUSTAINABILITY, RESILIENCE AND FOOD SECURITY IN THE NENA REGION: AN OVERVIEW
}

\author{
Feras Ziadat ${ }^{1}$, Pandi Zdruli ${ }^{2}$, Scott Christiansen ${ }^{3}$, Lucrezia Caon ${ }^{4}$, Mohamed \\ AbdelMonem $^{4}$, and Theodora Fetsi ${ }^{4}$ \\ ${ }^{1}$ Food and Agriculture Organization of the United Nations \\ ${ }^{2}$ CIHEAM \\ ${ }^{3}$ Independent Consultant \\ ${ }^{4} \mathrm{FAO}$
}

May 5, 2020

\begin{abstract}
Land degradation, desertification (LDD) and climate change are increasing in the Near East and North Africa (NENA) region, impacting the livelihoods of about 410 million people, food security and migration. Agriculture is a vital socio-economic sector, contributing on average 14 percent of the Gross Domestic Product (GDP) (excluding oil producing countries) and providing jobs and incomes for 38 percent of the region's economically active population. However, most NENA countries import at least 50 percent of the calories they consume. It is estimated that the total areas desertified or vulnerable to desertification cover 9.84 million $\mathrm{km} 2$ or about 86.7 percent of the total NENA region. Soil erosion by water and wind and sand and dust storms (SDS) causes losses of about USD 13 billion in GDP each year. But there are also opportunities to reverse these negative trends. Proper land use planning, prioritization of target areas for restoration and adoption of sustainable land and water management (SLWM) could reverse the situation. This paper analyses the inter-linkages between LDD resource base management and food security under different scenarios and offers mitigation and remediation options. These include knowledge management and sharing; establishment of a regional platform to facilitate dialogue; public and private investment opportunities; provision of tools to scale-out sustainable land and water options; and creation of a conducive enabling environment supported by policies and strategies.
\end{abstract}

\section{Hosted file}

Mediterranean LD and SLWM_V6.doc available at https://authorea.com/users/299844/articles/ 429401-combating-land-degradation-and-promoting-sustainability-resilience-and-foodsecurity-in-the-nena-region-an-overview 

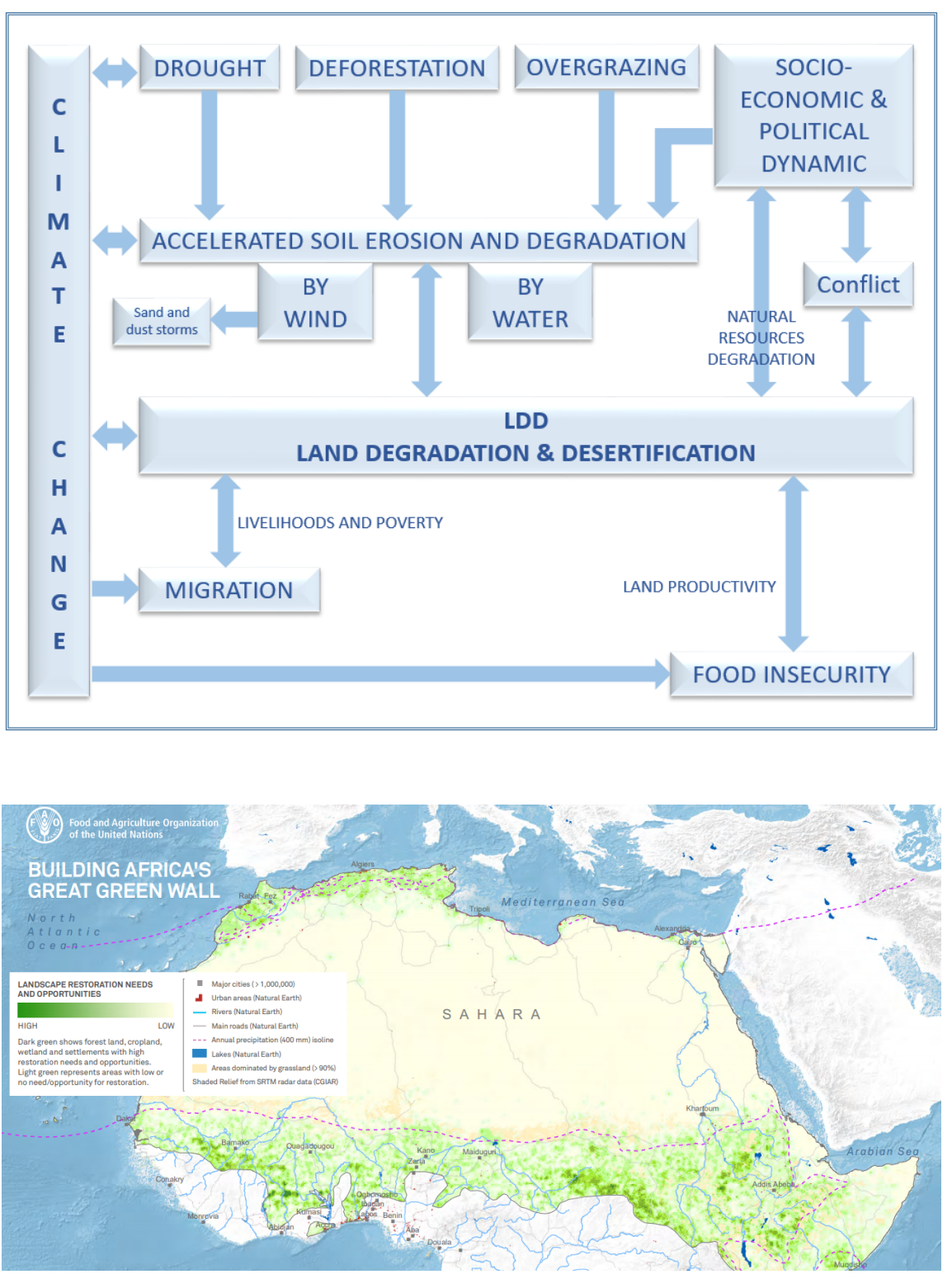

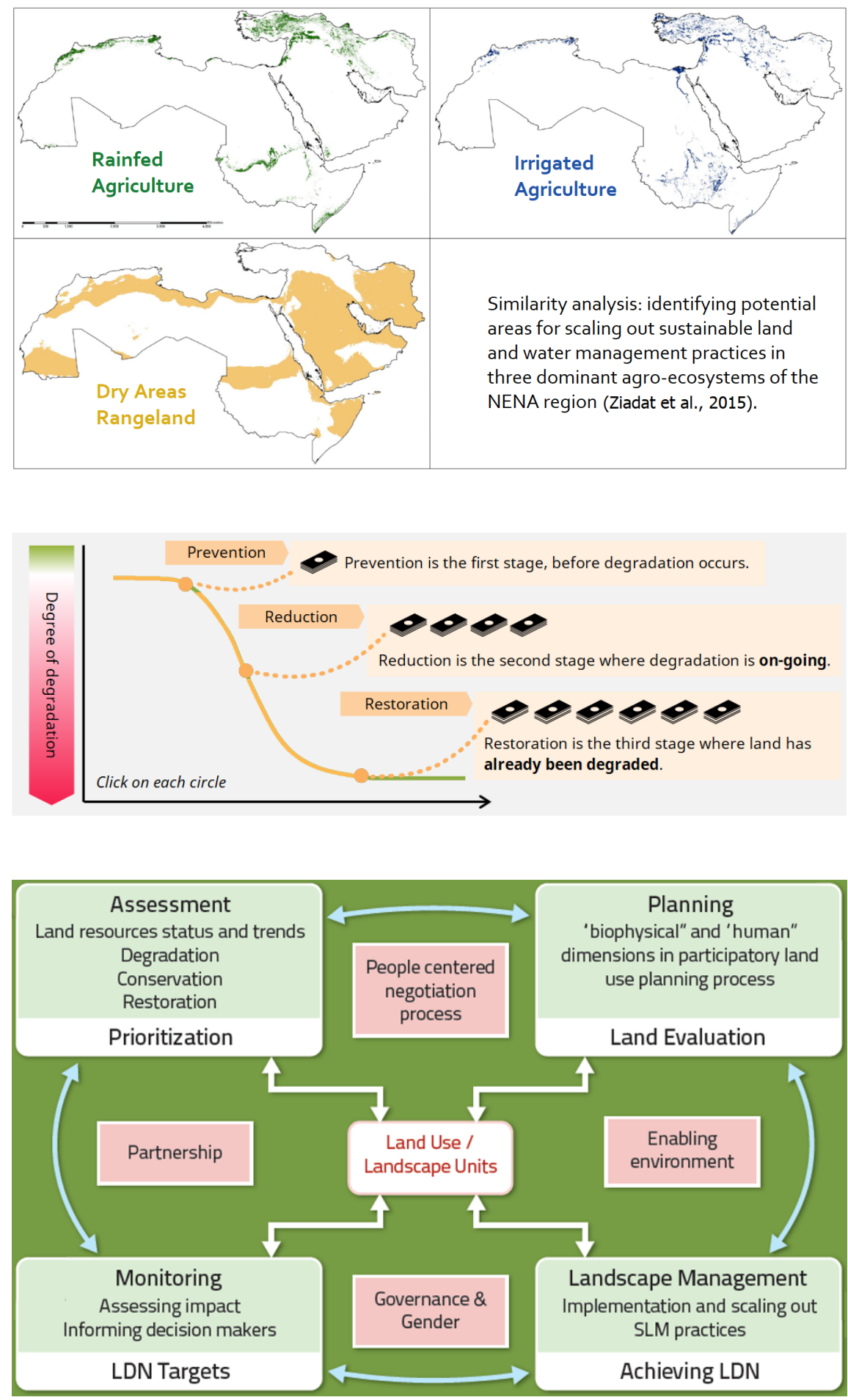


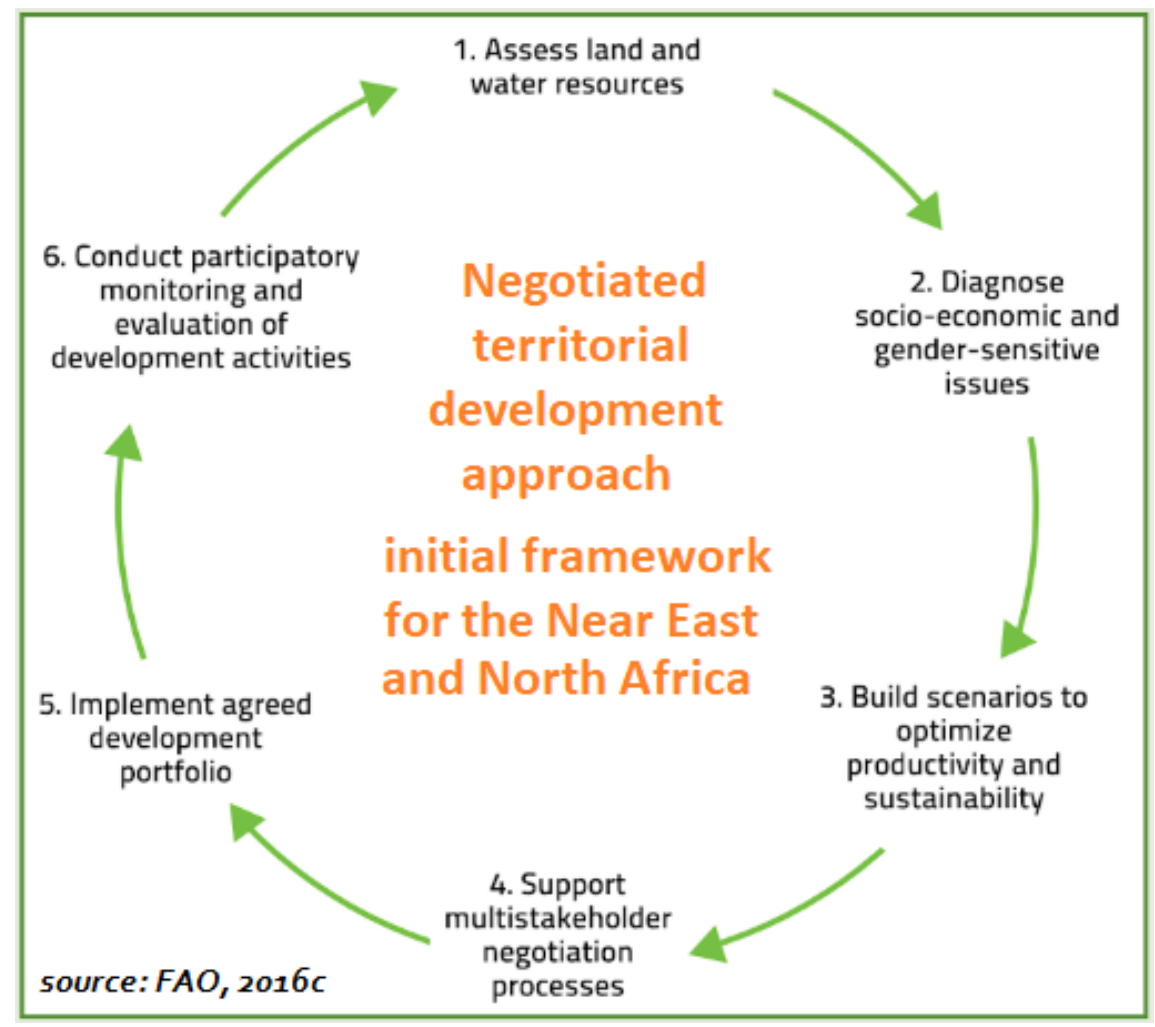

